JINOTEP 5 (1) Oktober (2018): 24-30

JINOTEP (Jurnal Inovasi Teknologi Pembelajaran)

Kajian dan Riset Dalam Teknologi Pembelajaran

http://journal2.um.ac.id/index.php/jinotep/index

\title{
PENGARUH SOCIAL LEARNING NETWORK TERHADAP MOTIVASI DAN HASIL BELAJAR SISWA
}

\author{
Mohammad Bariksah Athoillah, Sulton, Sulthoni
}

Teknologi Pembelajaran, Universitas Negeri Malang

\section{Article History}

Received: Oct 28, 2018

Accepted: March 22, 2019

Published:March 23, 2019

\section{Keywords}

Social learning network Motivasi

Hasil belajar

\begin{abstract}
Abstrak
Tujuan dari penelitian ini mengetahui pengaruh penggunaan social learning network terhadap motivasi dan hasil belajar siswa. Penelitian ini menggunakan metode penelitian eksperimen semu dengan menggunakan desain posttest only control group. Uji Hipotesis penelitian menggunakan uji-t serta uji $T^{2}$. Hasil uji hipotesis Uji-t motivasi belajar diperoleh $\mathrm{T}_{\text {hitung }}-5,187$ dengan nilai Sig. 0,000 $(<0,05)$, kesimpulannya H0 ditolak dan H1 diterima. Hasil uji hipotesis Uji-t hasil belajar diperoleh $\mathrm{T}_{\text {hitung }}-2,950$ dengan nilai Sig. 0,005 $(<0,05)$, kesimpulannya $\mathrm{H} 0$ ditolak dan $\mathrm{H} 1$ diterima. Hasil uji hipotesis $\mathrm{T}^{2}$ diperoleh nilai F 1,307 dengan nilai Sig. 0,000 $(<0,05)$, kesimpulannya H0 ditolak dan H1 diterima.
\end{abstract}

\begin{abstract}
The purpose of this study to know the influence of the use of social learning network to motivation and student learning outcomes. This research uses quasi experimental research method using posttest only control group design. Hypothetical test of research using t-test and T2 test. Result of hypothesis test The t-test of learning motivation obtained by Thitung -5,187 with Sig value. 0,000 $(<0,05)$, conclusion $\mathrm{HO}$ rejected and $\mathrm{H} 1$ accepted. Result of hypothesis test The $t$ test of learning result obtained by Thitung $-2,950$ with Sig value. 0,005 (<0,05), conclusion $\mathrm{HO}$ rejected and $\mathrm{H} 1$ accepted. Result of hypothesis $\mathrm{T} 2$ test obtained value of F 1,307 with value of Sig. 0,000 $(<0,05)$, conclusion HO rejected and H1 accepted.
\end{abstract}

Corresponding author :

Mohammad Bariksah Athoillah,

Teknologi Pembelajaran

Pascasarjana Universitas Negeri Malang

Jalan Semarang 5 Malang

E-mail: mohammad.bariksah@gmail.com
2018 Universitas Negeri Malang p-ISSN 2406-8780 e-ISSN 2654-7953 


\section{PENDAHULUAN}

Mutu pendidikan memiliki kaitan erat dengan kualitas lulusannya, sedangkan kualitas lulusannya ditentukan oleh keberhasilan atas keterlaksanaan kegiatan proses pembelajaran. Ada beberapa komponen dalam kegiatan proses pembelajaran diantaranya guru, siswa, dan bahan ajar. Menurut Sanjaya, W. (2006: 14) menjelaskan bahwa sebagai guru profesional, seorang guru bukan hanya menyampaikan materi pelajaran di depan kelas, namun guru harus memiliki beberapa kemampuan dalam merancang serta mampu mengamplikasikan berbagai strategi belajar yang dianggap sesuai minat dan bakat.

Sejalan dengan itu, dalam terselenggaranya proses pembelajaran diperlukan adanya suatu dukungan atau dorongan terhadap siswa dalam mengikuti proses belajar demi tercapainya tujuan yang diharapkan. Motivasi merupakan dorongan atau dukungan dari dalam yang membuat siswa untuk bertindak dalam mengerjakan sesuatu di saat siswa berada dalam kondisi yang membutuhkan (Sanjaya, 2006: 135). Sedangkan menurut Ibrahim, D.S., dkk. (2014, p.70) melakukan aktifitas yang didukung dengan adanya suatu dorongan atau kemauan yang kuat, maka akan memperoleh hasil yang memuaskan, begitu pula sebaliknya. Memotivasi siswa merupakan tanggungjawab seorang guru, guru harus memiliki kemampuan pedagogis yang baik dalam menghadapi siswa untuk mencapai tingkat keberhasilan dalam proses kegiatan belajarnya. Meningkatkan motivasi belajar siswa terasa kurang cukup untuk mengkategorikan proses pembelajaran berhasil tanpa adanya suatu patokan sebagai alat tolak ukur tingkat keberhasilan siswa. Hasil belajar sebagai tolak ukurnya.

Menurut Purwanto, (2009: 67) hasil belajar merupakan perubahan perilaku yang terjadi karena kegiatan pembelajaran. Sedangkan menurut Winkel dalam Purwanto (2009: 39) belajar merupakan aktifitas psikis yang dialami seseorang terhadap lingkungan sekitar yang mampu merubah perilaku seseorang dalam waktu yang lama. Sehingga hasil belajar dapat didefinisikan sebagai perubahan yang berdasarkan atas akibat terjadinya perubahan prilaku manusia. Aspek perubahan tersebut mengacu pada taksonomi yang dikembangkan oleh Bloom, Dkk. meliputi aspek kognitif, afektif, serta psikomotorik. Dalam aspek kognitif, adanya perubahan cara berfikir seseorang, aspek afektif adanya perubahan kemampuan cara merasakan, sedang aspek psikomotorik adanya perubahan keterampilan dalam diri seseorang. Berdasarkan hal tersebut, hasil belajar dapat didefinisikan sebagai suatu perolehan akhir atas adanya perubahan perilaku yang didapatkan oleh siswa melalui kegiatan belajar yang mencakup domain kognitif, afektif, psikomotorik yang sesuai dengan tujuan pendidikan yang berlaku pada suatu mata pelajaran.

Berawal dari semakin kompleksnya permasalahan yang dihadapi dalam pembelajaran konvensional, sehingga muncul suatu konsep pembelajaran berbasis internet sebagai upaya perbaikan yang dapat mengatasi berbagai permasalahan yang sulit diatasi dalam pembelajaran konvensional. Seiring berjalannya waktu, terjadilah suatu pergeseran dalam perkembangannya. Dengan kata lain, media tersebut dapat digunakan sebagai media pendukung untuk lebih memudahkan terjadinya proses pembelajaran antara siswa dengan guru serta mampu menjembatani jarak antara siswa dengan orang tua. Perkembangan di bidang teknologi saat ini sangat memberikan kontribusi besar dalam bidang pendidikan. Hal tersebut bisa dibuktikan oleh adanya pemanfaataan $e$ learning sebagai media bantu dalam proses pembelajaran.

Menurut Munawaroh, I. (2005) e-learning adalah sistem pem-belajaran jarak jauh yang merupakan konsep pembelajaran lama yang telah mendapatkan pengakuan dunia. Adanya pengakuan tersebut dianggap mampu menjawab berbagai permasalahan belajar serta semakin meningkatnya kesadaran tetang proses pembelajaran sepanjang hayat (Long Life Education). Pembelajaran virtual merupakan bagian dari e-learning. Menurut Munawaroh, I. (2005: 171) pembelajaran virtual secara konseptual memiliki potensi dalam 
26 JINOTEP (Jurnal Inovasi dan Teknologi Pembelajaran) Kajian dan Riset dalam Teknologi Pembelajaran Vol. 5, No. 1, Oktober 2018, Hal. 24-30

meningkatkan kualitas pendidikan, diantaranya potensi dalam memberikan peluang berkomunikasi antara siswa dan guru serta bahan belajar yang tidak terpengaruh oleh kendala tempat serta tempat dan mampu memberikan sajian bahan ajar yang mampu memotivasi siswa untuk belajar.

Proses Pembelajaran virtual yang dimaksud adalah pembelajaran berbasis social learning network (Edmodo). edmodo mampu menyediakan akses virtual yang setara dengan kelas, seperti konten-konten kelas, tes evaluasi, pekerjaan rumah dan sebagai sumber informasi akademis. Edmodo merupakan ruang yang rasional dimana siswa dan guru dapat berinteraksi seperti diskusi dan chatting dengan menggunakan alat untuk berinteraksi 2 arah atau lebih serta orang tua memiliki peran ikut serta di dalamnya. Edmodo didesain secara khusus untuk menunjang proses pembelajaran.

Desain dari edmodo itu sendiri mengadopsi pada situs jejaring sosial (social network) yang banyak digemari oleh kalangan mudah, namun bersifat private (terbatas), hanya bisa digunakan oleh guru, siswa dan orang tua yang terdaftar saja. Serta mempunyai fleksibilitas penggunaannya yang tidak terbatas pada waktu dan tempat, dan bisa digunakan melalui berbagai device (PC/Laptop, Tablet, dan Handphone) yang terkoneksi jaringan internet. Sehingga edmodo merupakan platform yang tepat untuk bisa digunakan sebagai media penunjang dalam proses pembelajaran, dimana terdapat peran serta orang tua yang memiliki andil yang cukup besar terhadap motivasi dan perkembangan psikologis siswa dalam mengikuti proses pembelajaran.

Sebagai orang tua, seyogyanya bisa mengetahui proses perkembangan belajar anak meskipun jarak memisahkan antar keduanya. Orang tua harus bisa menumbuhkan hubungan erat dengan anak demi memotivasi keberhasilan belajar anak. Hubungan jarak antara anak dan orang tua yang berlainan tempat tinggal tidak serta merta menjadi penghambat proses pembelajaran.

\section{METODE}

Metode penelitian yang digunakan adlah quasi eksperiment. Desain penelitian eksperimen mengunakan desain posttest-only control group. Tahap-tahap dalam menggunakan desain eksperimen tersebut menurut Gall dan Borg, (2003, p.392) dapat diartikan sebagai berikut: (1) subyek penelitian dipilih secara acak; (2) memberi perlakuan kelompok eksperimen saja; (3) memberikan posttest kedua kelompok.

Variabel penelitian mencakup 3 variabel, yaitu social learning network sebagai variabel bebas, motivasi belajar sebagai dan hasil belajar sebagai variabel terikat.

Subyek penelitian mencakup 2 lokal, yaitu kelas VIII lokal 1 sebagai kelas eksperimen berjumlah 29 siswa dan kelas VIII lokal 3 sebagai kelas kontrol berjumlah 28 siswa. Dengan asumsi, kemampuan siswa dalam pengetahuan di bidang IT berbasis internet ratarata sama, minat siswa dalam mengoperasikan teknologi komputer berbasis internet cukup besar, adanya dukungan dari lembaga/institusi dalam menerapkan media pembelajaran social learning network, aktivitas pembelajaran berbasis internet tidak berbenturan dengan aturan kebijakan lembaga pesantren, sarana prasarana sekolah (internal) berupa laboratorium komputer dan adanya beberapa warnet lingkungan pesantren (ekternal) cukup memadai.

Instrumen penelitian menggunakan angket motivasi yang sudah baku untuk menghindari rasa keraguan atas validitas dan reliabilitas suatu angket, sehingga mempermudah peneliti dalam melaksanakan proses penelitian. Hasil belajar mengacu pada nilai rapot yang sudah ada, sehingga mempermudah peneliti dalam mengetahui hasil belajar siswa. Analisa data yg digunakan sebagai uji prasyarat dengan uji normalitas Kolmogorov-Smirnov, uji homogenitas dengan Uji Leven's. Sedangkan uji hipotesis dengan Uji-t dan uji $T^{2}$ Hotteling Trace (manova).

\section{HASIL}

Sebelum data dianalisis, terlebih dahulu mendeskripsikan distribusi frekuensi data 
motivasi dan data hasil belajar baik kelas kontrol maupun kelas eksperimen.

Berdasarkan batasan kategori yang telah ditentukan, distribusi frekuensi data motivasi kelompok kontrol yang terdiri dari 28 siswa diperoleh 22 siswa $(75,86 \%)$ mempunyai motivasi tinggi, 6 siswa $(20,69 \%)$ mempunyai motivasi sedang, 1 siswa $(3,45 \%)$ mempunyai motivasi yang tinggi sekali, dan tidak adanya siswa yang memiliki motivasi yang rendah bahkan rendah sekali. Sedangkan distribusi frekuensi data motivasi kelompok eksperimen yang terdiri dari 29 siswa diperoleh 19 siswa $(67,86 \%)$ mempunyai motivasi tinggi, 6 siswa $(28,57 \%)$ mempunyai motivasi tinggi sekali, 1 siswa $(3,57 \%)$ mempunyai tingkat motivasi sedang, dan tidak ada siswa yang memiliki tingkat motivasi yang rendah dan rendah sekali.

Berdasarkan batasan kategori yang telah ditentukan, distribusi frekuensi data hasil belajar kelompok kontrol yang terdiri dari 28 siswa diperoleh bahwa 9 siswa $(31,03 \%)$ mempunyai nilai hasil belajar antara 80-82, sebanyak 5 siswa $(17,23 \%)$ mempunyai nilai hasil belajar antara 83-85, sebanyak 7 siswa $(24,14 \%)$ mempunyai nilai hasil belajar antara $86-88$, sebanyak 3 siswa $(10,34 \%)$ mempunyai nilai hasil belajar antara 89,91, sebanyak 3 siswa $(10,34 \%)$ mempunyai nilai hasil belajar antara 92-94, dan sebanyak 2 siswa $(6,90 \%)$ mempunyai nilai hasil belajar antara 95-97.

Sedangkan distribusi frekuensi data hasil belajar kelompok eksperimen yang terdiri dari 29 siswa diperoleh bahwa 3 siswa $(10,71 \%)$ mempunyai nilai hasil belajar antara 78-81, sebanyak 1 siswa $(3,57 \%)$ mempunyai nilai hasil belajar antara $82-85$, sebanyak 8 siswa $(28,57 \%)$ mempunyai nilai hasil belajar antara $86-89$, sebanyak 6 siswa $(21,43 \%)$ mempunyai nilai hasil belajar antara 90-93, sebanyak 7 siswa $(25,00 \%)$ mempunyai nilai hasil belajar antara 94-97 dan sebanyak 3 siswa $(10,71 \%)$ mempunyai nilai hasil belajar antara 98-101. Setelah mengetahui data motivasi dan hasil belajar dari kedua kelompok, hasil uji normalitas bisa dilihat dalam tabel 1 .

Tabel 1. Uji Normalitas

\begin{tabular}{clccc}
\hline No & \multicolumn{1}{c}{ Variabel } & KS hitung & Sig. & Kesimpulan \\
\hline 1 & Motivasi belajar kelompok kontrol & 0,642 & 0,804 & Normal \\
2 & Motivasi belajar kelompok eksperimen & 0,761 & 0,609 & Normal \\
3 & Hasil belajar kelompok kontrol & 0,601 & 0,863 & Normal \\
4 & Hasil belajar kelompok eksperimen & 0,767 & 0,599 & Normal \\
\hline
\end{tabular}

Berdasarkan pada tabel 1, diperoleh bahwa semua nilai Sig. yang melalui uji KomogorovSmirnov adalah $>0,05$, sehingga Ho diterima. Bisa disimpulkan, bahwasannya semua data dalam penelitian terdistribusi secara normal. Setelah mengetahui data penelitian terdistribusi secara normal, hasil uji homogenitas bisa dilihat pada tabel 2 .

Tabel 2. Uji Homogenitas

\begin{tabular}{cccc}
\hline Variabel & F & Sig. & Ket. \\
\hline $\begin{array}{c}\text { Motivasi } \\
\text { belajar }\end{array}$ & 0,582 & 0,449 & Homogen \\
$\begin{array}{c}\text { Hasil belajar } \\
0,387\end{array}$ & 0,537 & Homogen \\
\hline
\end{tabular}

Berdasarkan pada tabel 2, melalui uji Leven's diperoleh bahwa harga F sebesar 0,582 dengan Sig. sebesar 0,449 untuk variabel motivasi belajar, dan $\mathrm{F}$ sebesar 0,387 dengan Sig. sebesar 0,537. Ternyata harga Sig. $>0,05$., sehingga Ho diterima. Dapat disimpulkan bahwa varian populasi data bersifat homogen. Setelah mengetahui data penelitian terdistribusi secara dan homogen. Selanjutnya melakukaan uji hipotesis, hipotesis pertama bisa dilihat dalam tabel 3. 
28 JINOTEP (Jurnal Inovasi dan Teknologi Pembelajaran) Kajian dan Riset dalam Teknologi Pembelajaran Vol. 5, No. 1, Oktober 2018, Hal. 24-30

Tabel 3. Analisis Uji-t Motivasi Belajar

\begin{tabular}{lccccc}
\hline \multicolumn{1}{c}{ Motivasi Siswa } & N & Rerata & T hitung & Sig. & Ket. \\
\hline Kelompok kontrol & 29 & 123,62 & $-5,187$ & 0,000 & Signifikan \\
Kelompok eksperimen & 28 & 135,32 & & & \\
\hline
\end{tabular}

Berdasarkan tabel 3, diperoleh bahwa $\mathrm{T}_{\text {hitung }}$ $=-5,187$ dan nilai Sig. adalah 0,000. lebih kecil dari $0,05(<0,05)$, sehingga $\mathrm{H} 0$ ditolak dan $\mathrm{H} 1$ diterima. Bisa disimpulkan, bahwasannya ada perbedaan motivasi belajar antara siswa yang dibelajarkan meng-gunakan social learning network. Selanjutnya melakukan uji hipotesis kedua bisa dilihat pada tabel 4 .

Tabel 4. Hasil Analisis Uji-t Hasil Belajar

\begin{tabular}{lccccc}
\hline \multicolumn{1}{c}{ Hasil Belajar Siswa } & N & Rerata & T hitung & Sig. & Ket. \\
\hline Kelompok kontrol & 29 & 86,10 & $-2,950$ & 0,005 & Signifikan \\
Kelompok eksperimen & 28 & 90,36 & & & \\
\hline
\end{tabular}

Berdasarkan tabel 4, diperoleh bahwa $\mathrm{T}_{\text {hitung }}$ $=-2,950$ dan nilai Sig. adalah 0,005., lebih kecil dari $0,05(<0,05)$, sehingga $\mathrm{H} 0$ ditolak, dan $\mathrm{H} 1$ diterima. Bisa disimpulkan, bahwasannya ada perbedaan motivasi belajar antara siswa yang dibelajarkan meng-gunakan social learning network. Selanjutnya melakukan uji hipotesis selajutnya (ketiga) bisa dilihat dalam tabel 5 .

Tabel 5. Hasil Analisis Uji T (manova)

\begin{tabular}{|c|c|c|c|}
\hline Analisis & $F_{\text {hitung }}$ & Sig. & Ket. \\
\hline Pillais Trace & 1,307 & 0,000 & \multirow{4}{*}{ Signifikan } \\
\hline Wilks Lambda & 1,307 & 0,000 & \\
\hline Hotellings Trace & 1,307 & 0,000 & \\
\hline Roys Largest Root & 1,307 & 0,000 & \\
\hline
\end{tabular}

Berdasarkan tabel 5, diperoleh bahwa nilai $\mathrm{F}$ pada Pillai's Trace, Wilks' Lambda, Hotelling's Trace, Roy's Largest Root $=1,307$ dan nilai Sig. adalah 0,000., lebih kecil dari 0,05 $(<0,05)$, sehingga H0 ditolak dan H1 diterima. Dengan demikian bisa disimpulkan bahwa ada pengaruh penggunaan social learning network terhadap motivasi dan hasil belajar siswa.

\section{PEMBAHASAN}

Berdasarkan data analisis dan pengujian hipotesis pertama, bahwa ada perbedaan motivasi belajar siswa antara siswa yang dibelajarkan menggunakan social learning network. Nilai rerata yang diperoleh sebesar
123,62 pada kelompok kontrol dan 135,32 pada kelompok eksperimen. Ternyata motivasi belajar siswa kelas eksperimen lebih tinggi daripada siswa kelas kontrol, berarti mendapat kesimpulan bahwa pembelajaran dengan menggunakan social learning network lebih menarik daripada pembelajaran biasa, sehingga mampu meningkatkan motivasi belajar siswa dalam mengikuti proses pembelajaran.

Berdasarkan data analisis dan pengujian hipotesis kedua, bahwa ada perbedaan hasil belajar antara siswa yang dibelajarkan menggunakan social learning network. Nilai rerata yang diperoleh sebesar 86,10 pada kelompok kontrol dan 90,36 pada kelompok eksperimen. Ternyata hasil belajar siswa pada 
kelas eksperimen lebih baik daripada siswa kelas kontrol. Berarti menunjukkan bahwa kegiatan pembelajaran menggunakan social learning network lebih menarik daripada pembelajaran biasa, sehingga mampu meningkatkan hasil belajar siswa dalam mengikuti proses pembelajaran (Yunkul, 2017)

Berdasarkan data analisis dan pengujian hipotesis ketiga, bahwa ada pengaruh penggunaan social learning network terhadap motivasi dan hasil belajar siswa. Nilai rerata motivasi sebesar 123,62 kelompok kontrol dan 135,32 pada kelompok eksperimen, serta nilai hasil belajar sebesar 86,10 pada kelompok kontrol dan 90,36 pada kelompok eksperimen. Ternyata baik nilai motivasi belajar maupun nilai hasil belajar siswa pada kelas eksperimen lebih baik daripada siswa kelas kontrol, dan pengujian $\mathrm{T}^{2}$ (manova) menunjukkan bahwa ada pengaruh yang signifikan dari social learning network terhadap motivasi dan hasil belajar siswa (Ferguson, 2012).

Hal ini berarti bahwa pembelajaran menggunakan social learning network lebih menarik daripada pembelajaran biasa, sehingga mampu meningkatkan motivasi dalam proses pembelajarannya, dan nilai hasil belajar yang diperoleh siswa pun lebih baik daripada siswa yang proses pembelajarannya tidak menggunakan social learning network. Memperhatikan hasil penelitian ini, maka seorang guru dapat memilih pembelajaran menggunakan social learning network dalam proses pembelajaran karena dapat meningkatkan motivasi dan hasil belajar siswa (Greenhow,2009).

Sejalan dengan penelitian yang pernah dilakukan oleh Ibrahim (2014), hasil penelitian yang dilakukan menunjukkan bahwa ada pengaruh positif pengguna e-learning terhadap motivasi dan prestasi belajar siswa. Sejalan dengan pendapat Munawaroh, I. (2005: 171) pembelajaran virtual secara konseptual memiliki potensi dalam meningkatkan kualitas pendidikan, diantaranya potensi dalam memberikan peluang berkomunikasi antara siswa dan guru serta bahan belajar yang tidak terpengaruh oleh kendala tempat serta tempat dan mampu memberikan sajian bahan ajar yang mampu memotivasi siswa untuk belajar. Berdasarkan adanya beberapa fakta tersebut, mempertegas bahwa social learning network mampu memberi pengaruh signifikan terhadap motivasi dan hasil belajar siswa.

\section{SIMPULAN DAN SARAN Simpulan}

Berdasarkan beberapa hal di atas, bisa disimpulkan ada perbedaan motivasi dan hasil belajar siswa yang dibelajarkan dengan menggunakan social learning network, serta ada pengaruh social learning network terhadap motivasi dan hasil belajar siswa.

\section{Saran}

Bagi mahasiswa, agar kelak ketika menjadi guru dapat memilih serta menggunakan metode yang sesuai agar memperoleh hasil belajar yang maksimal. Bagi guru, agar tetap obyektif dan konsisten dalam memberikan nilai terhadap siswa, serta tidak terpengaruh siapa latar belakang siswa tersebut. Bagi lembaga, agar memberikan kelonggaran bagi guru untuk mengembangkan kemampuan mengajarnya sehingga dapat memilih metode mengajar yang tepat.

\section{DAFTAR RUJUKAN}

Ferguson, R., \& Shum, S. B. (2012, April). Social learning analytics: five approaches. In Proceedings of the 2nd international conference on learning analytics and knowledge (pp. 23-33).

Greenhow, C., \& Robelia, B. (2009). Old communication, new literacies: Social network sites as social learning resources. Journal of computer-mediated communication, 14(4), 1130-1161.

Ibrahim, D.S. \& Suardiman, S.P. 2014. Pengaruh Penggunaan E-Lerning Terhadap Motivasi dan Prestasi Belajar Matematika Siswa SD Negeri Tahunan Yogyakarta. Jurnal Prima Edukasia, 2 (1): 66-79.

Munawaroh, I. 2005. Virtual Learning Dalam Pembelajaran Jarak Jauh. Majalah Ilmiah Pembelajaran, 1 (2): 171-181. 
30 JINOTEP (Jurnal Inovasi dan Teknologi Pembelajaran) Kajian dan Riset dalam Teknologi Pembelajaran Vol. 5, No. 1, Oktober 2018, Hal. 24-30

Purwanto, 2009. Evaluasi Hasil Belajar. Yogyakarta: Pustaka Belajar.

Sanjaya, Wina. 2006. Strategi Pembelajaran: Berorientasi Standar Proses Pendidikan. Jakarta: Kencana Prenadamedia Group.
Yunkul, E., \& Cankaya, S. (2017). Students' attitudes towards Edmodo, a social learning network: A scale development study. Turkish Online Journal of Distance Education, 18(2), 16-29. 